\title{
CDCA3 is a potential prognostic marker that promotes cell proliferation in gastric cancer
}

\author{
YAN ZHANG ${ }^{1}$, WEI YIN ${ }^{2}$, WEI CAO ${ }^{3}$, PEISHENG CHEN $^{2}$, LONGJUN BIAN $^{2}$ and QINGFENG NI $^{2}$ \\ Departments of ${ }^{1}$ Oncology, ${ }^{2}$ General Surgery and ${ }^{3}$ Gastroenterology, \\ Affiliated Hospital of Nantong University, Nantong, Jiangsu 226001, P.R. China
}

Received March 17, 2018; Accepted February 1, 2019

DOI: $10.3892 /$ or.2019.7008

\begin{abstract}
Gastric cancer (GC) is an aggressive and highly lethal gastrointestinal cancer, with an exceedingly poor prognosis. In the present study, the carcinogenic mechanism of human GC and the role of cell division cycle-associated 3 (CDCA3) were investigated. The expression levels of CDCA3 were investigated in GC samples and matched, peritumoral tissues by reverse transcription-quantitative polymerase chain reaction and immunohistochemical analysis. The effects of CDCA3 on cell proliferation were explored by Cell Counting Kit-8, colony formation, flow cytometric analysis and western blotting in vitro, and in vivo tumorigenesis in nude mice. The results demonstrated that CDCA3 expression was increased in human GC tissues compared with those in adjacent non-tumor tissues. Evaluation of the clinicopathological significance indicated that CDCA3 was closely associated with features of GC and patients with unfavorable overall survival times. CDCA3 overexpression resulted in the stimulation of cell growth and colony formation in vitro and xenograft tumors in vivo. Conversely, knockdown of CDCA3 inhibited these effects. Furthermore, the ectopic expression of CDCA3 in SGC7901 cells consistently promoted the cell cycle transition from the $\mathrm{G}_{0} / \mathrm{G}_{1}$ phase to the $\mathrm{S}$ phase; whereas knockdown of CDCA3 in BGC823 cells blocked the transition from the $\mathrm{G}_{0} / \mathrm{G}_{1}$ phase. Additionally, the present study revealed that the Ras signaling pathway was involved in CDCA3-mediated regulation of GC cell proliferation. CDCA3 activated the Ras signaling pathway to promote cell proliferation in vitro and in vivo in GC cells. Levels of CDCA3 greatly accelerated the progression of human GC. CDCA3 served as an oncogene, and may be a significant prognostic predictor and a novel therapeutic target for patients with $\mathrm{GC}$.
\end{abstract}

Correspondence to: Dr Qingfeng Ni, Department of General Surgery, Affiliated Hospital of Nantong University, 20 Xisi Road, Nantong, Jiangsu 226001, P.R. China

E-mail: qfni19841116@sina.com

Key words: gastric cancer, CDCA3, cell proliferation, Ras signaling pathway, prognosis

\section{Introduction}

As the nutritional status, sanitation, refrigeration and access to fresh fruits and vegetables have improved; the incidence of gastric cancer (GC) appears to be decreasing in many nations over the last few decades (1-3). GC represents the third most common cause of cancer-associated mortality worldwide (4). The etiological agent of GC is complicated, and ascribed to assorted diet and environmental and genetic factors (5). Multifarious treatments including surgical resection, neoadjuvant chemical therapy, radiation treatment and targeted molecular therapy have become pivotal treatments to prevent disease evolvement. The 5 -year survival rate of patients with GC is $<20 \%$ worldwide, particularly in eastern Asia and China (6-8). Traditionally, cancer prognosis is based on the depth of tumor infiltration, the occurrence of lymph node and long-distance metastases, which can be evaluated by microscopic examination of pathology (9). The unfavorable prognosis associated with GC has compelled for the development of novel diagnostic markers. However, the potential pathogenic mechanisms underlying GC progression have not been completely elucidated. As a result, it is essential to illuminate neoteric molecular approaches to ameliorate existing prognostic stratification and provide relevant critical clinical insights into assessing the outcome of patients with GC.

Cell division cycle-associated 3 (CDCA3), also known as Tome-1 (trigger of mitotic entry), was initially detected during the degradation process of intra-cellular protein induced by APCCDH1 $(10,11)$. CDCA3 of human beings is located on chromosome 12p12, is composed of 268 amino acids and has a molecular weight of $29 \mathrm{kDa}$ (12). CDCA3 contains an F-box motif, which is available to combine with Skp1 and cullin, and to regulate numerous physiological and pathological processes in the human body by stimulating the degradation of certain proteins such as cell cycle-regulating proteins, transcription factors and signal transduction molecules $(13,14)$. Recent investigations have suggested that CDCA 3 serves a key role in the development of various types of cancers (15-19). Recent studies demonstrated that there is a high expression of CDCA3 in oral squamous cell carcinoma, and it has the capacity to promote the growth and proliferation of tumor cells by regulating mitosis (20). O'Byrne et al reported that CDCA3 was markedly upregulated and associated with poor prognosis in non-small cell lung cancer (NSCLC) and highlighted CDCA3 
as a novel factor in mediating NSCLC cell proliferation (21). CDCA3 was revealed to serve a key role in tumorigenesis and the development of esophageal carcinoma, and was involved in the cell cycle and endocytosis (22). High expression of CDCA3 has also been observed in liver cells, and has prognostic significance in patients with hepatocellular carcinoma $(15,18)$. In addition, prostate cancer progression could be promoted by upregulating CDCA3 expression, and CDCA3 may serve as a potential therapeutic target for human prostate cancer (17). However, the expression of CDCA3 in GC cell lines and tissues and the association between CDCA 3 expression and the survival outcome of patients with GC remain poorly understood, and furthermore, the precise effect of CDCA3 on GC progression remains obscure.

In the present study, a novel oncogene was identified and its expression profile in GC tissues and cell lines was evaluated by employing reverse transcription-quantitative polymerase chain reaction (RT-qPCR) and immunohistochemical analysis. An association between CDCA3 expression and clinicopathological features of patients with GC was discovered, and the merits of prognosis for the accurate predictability for the survival of patients with GC was analyzed. The present study demonstrated that the expression of CDCA3 influenced GC cell proliferation in vitro and vivo, in particular with respect to its signaling pathways by which CDCA3 may mediate GC cell progression. These findings demonstrated that CDCA3 may provide an increased understanding into predicting a poor outcome, and be applied to the diagnosis and treatment of patients with GC.

\section{Materials and methods}

Tissue specimens and cell lines. GC tissues and paired normal adjacent mucosa tissues were derived from 150 patients with GC who had undergone surgical resection at the Department of General Surgery, The Affiliated Hospital of Nantong University (Nantong, China). Histological classifications and tumor-node-metastasis (TNM) stages were independently determined by two senior pathologists according to the classification criteria of the American Joint Committee on Cancer. Resected samples were snap-frozen in liquid nitrogen until RNA and protein extraction could be performed. Tissue specimens were flash frozen immediately following surgery and stored in liquid nitrogen until RNA extraction. All patients provided written informed consent prior to surgery and the Ethics Committee of Affiliated Hospital of Nantong University, approved the present study. Signed informed consents were obtained from all subjects and no scientific research was conducted without the informed contents. Nantong University approved the present study. The study was approved by the Ethics Committee of the Affiliated Hospital of Nantong University. All procedures performed in this study were in accordance with the 1964 Helsinki Declaration and its later amendments.

Five human GC cell lines (BGC823, AGS, MKN45,MKN28 and SGC7901) and a human normal gastric epithelial cell line (GES-1) were purchased from the American Type Culture Collection (ATCC; Manassas, VA, USA), and the National Infrastructure of Cell Line Resource (Beijing, China). The cell lines were maintained in RPMI-1640 medium supplemented with $10 \%$ fetal bovine serum (FBS), ampicillin and streptomycin, in a humidified chamber at $37^{\circ} \mathrm{C}$ with $5 \% \mathrm{CO}_{2}$.

$R T-q P C R$. Total RNA was isolated from paired GC and adjacent non-tumor tissues, 5 human GC cell lines and GES-1 cells by employing TRIzol reagent (Invitrogen; Thermo Fisher Scientific, Inc., Waltham, MA, USA) according to the manufacturer's protocol. PrimeScript RT reagent (Takara Bio, Inc., Otsu, Japan) was used to transcribe isolated total RNA into cDNA and then SYBR Premix Ex Taq (Takara Bio, Inc.) was used to evaluate mRNA expression levels by quantitative real-time PCR assays. The primer sequences were as follows: CDCA3 sense, 5'-TGGTATTGCACGGACACCTA-3' and antisense, 5'-TGTTTCACCAGTGGGCTTG-3'; $\beta$-actin sense, 5'-AGAGCCTCGCCTTTGCCGATCC-3' and antisense, 5'-CTGGGCCTCGTCGCCCACATA-3'. All experiments were run in triplicate.

Immunohistochemical (IHC) staining. Paraffin-embedded sections (4- $\mu \mathrm{m}$ thick) were incubated with polyclonal rabbit anti-CDCA3 antibody (dilution 1:200; cat. no. ab167037; Abcam, Cambridge, UK) at $4^{\circ} \mathrm{C}$ overnight using SP-9000 Histostain $^{\mathrm{TM}}$-Plus kits (ZSGB-BIO; OriGene Technologies, Inc., Beijing, China) according to the manufacturer's protocol. The immunoreactive scores (IRS) for the proportion of positive cells and he staining grade were calculated for each specimen. The quantity score evaluating the proportion of positive cells of CDCA3 was scored as 0 (negative), 1 (1-10\% labeled cells), 2 (11-50\% labeled cells), 3 (>50\% labeled cells). The intensity score evaluating the intensity of staining was scored as 0 (negative staining), 1 (weakly positive), 2 (moderately positive) and 3 (strongly positive). Multiplication of the extent scores and the staining intensity was performed to calculate the IRS and 3 was the optimal cutoff value: Samples with an IRS $\geq 3$ were defined as high CDCA3 expression and samples with an IRS $<3$ were regarded as low CDCA3 expression.

Construction of recombinant plasmids. Based on the CDCA3 nucleotide sequence from the human cDNA library (GenBank: NM_001297602.2), the full-length open reading frame (ORF) of the human CDCA3 gene was amplified using polymerase chain reaction according to the manufacturer's protocol (PrimeStar PCR; Takara Bio, Co., Ltd., Dalian, China). For the construction of CDCA3, the expression vector pcDNA3.1B containing the full-length open reading frame (ORF) of the human CDCA3 gene was used to generate pcDNA3.1B-CDCA3. The sequence of the forward primer was as follows: 5'-EcoRI-AGAGAATTCATGGGCTCAGCC AAGAGCGT-3', and sequence of the reverse primer was 5'-BamHI-AGAGGATCCCTAGCTCTCCACCAAGGGA-3'. The construct was verified by sequencing.

Short hairpin RNA preparation. Small interference RNAs were chemically synthesized (Shanghai GenePharma Co., Ltd., Shanghai, China).The sequence of siRNA-1069 was: 5'-GGGUACCCAGUUAUCUGUUGAGGAAdTdT-3' (sense) and 5'-UUCCUCAACAGAUAACUGGGUACCCdTdT-3' (antisense). Negative control (NC) siRNA synthesized by Shanghai GenePharma Co. was used as a control. The sequence of si-NC was as follows: 5'-UUCUCCGAACGUGUCACG 
UTT-3' (sense) and 5'-ACGUGACACGUUCGGAGAATT-3' (antisense). Synthesized DNA nucleotide fragment encoding shRNA against endogenous CDCA3 was designed according to the Invitrogen (Thermo Fisher Scientific, Inc.) and synthesized by GenePharma Co., Ltd. The sequences were incorporated into the Vector p-SUPER (OligoEngine, Seattle, WA, USA) to generate p-SUPER-sh-1069. The sequence of sh-1069 was as follows: 5'-GATCCCCGGGTACCCAGTTATCTGTTG AGGAATTCAAGAGATTCCTCAACAGATAACTGGGTA CCCTTTTTGGAAA-3' (sense) and 5'-AGCTTTTCCAAA AAGGGTACCCAGTTATCTGTTGAGGAATCTCTTGAA TTCCTCAACAGATAACTGGGTACCCGGG-3' (antisense). The sequence of sh-NC was as follows: 5'-GATCCCCTTCTC CGAACGTGTCACGTTTCAAGAGAACGTGACACGTTC GGAGAATTTTTGGAAA-3' (sense) and 5'-AGCTTTTCC AAAAATTCTCCGAACGTGTCACGTTCTCTTGAAACG TGACACGTTCGGAGAAGGG-3' (antisense). The constructs were verified by sequencing.

Cell transfection. BGC823 and SGC7901 cells were plated in each well of 6-well plates at a density of $5 \times 10^{4}$ cells/well. BGC823 cells were transfected with p-SUPER-sh-1069 and p-SUPER-sh-NC, SGC7901 cells were transfected with pcDNA3.1B-CDCA3 and pcDNA3.1B, respectively. Lipofectamine 2000 (Invitrogen; Thermo Fisher Scientific, Inc.) was used according to the manufacturer's protocol and transfection was conducted when cells reached $\sim 80 \%$ confluency. After transfection, we determined transfection efficiency and conducted subsequent functional experiments.

Cell proliferation assay. The transfected cells were seeded at a density of 2,000 cells/well in 96-well plates at daily intervals (every $24 \mathrm{~h}$ for 5 days) and Cell Counting Kit-8 (Dojindo Molecular Technologies, Inc., Kumamoto, Japan) was used according to the manufacturer's protocol. The absorbance was measured at $450 \mathrm{~nm}$ to evaluate the growth curve of transfected cells. All experiments were run in triplicate.

Colony formation assay. Each type of SGC7901 (SGC7901 transfected with pcDNA3.1B-CDCA3 SGC7901 transfected with pcDNA3.1B) and BGC823 (BGC823 transfected with p-SUPER-sh-1069 BGC823 transfected with p-SUPER-sh-NC) cells were seeded into 6-well plates at a density of 500 cells/well, and then maintained for 3 weeks in RPMI-1640 medium supplemented with $10 \%$ FBS, ampicillin and streptomycin containing G418 (1,000 $\mu \mathrm{g} / \mathrm{ml})$. Paraformaldehyde (4\%) (Invitrogen; Thermo Fisher Sceintific, Inc.) was employed to fix proliferating colonies for $30 \mathrm{~min}$ at room temperature, which were then stained with $1 \%$ crystal violet for $120 \mathrm{~min}$ at room temperature. The stained colonies were photographed under a light microscope (Leica Microsystems GmbH, Wetzlar, Germany; magnification, $\mathrm{x} 40$ ), the numbers of colonies ( $>50$ cells/colony) were counted. All experiments were run in triplicate.

Tumorigenicity assay in nude mice. Sixty BALB/c nude male mice, 4-weeks old, were purchased from the Department of Laboratory Animal Center, Nantong University (Nantong, China). Animal experiments were performed according to the protocol approved by the Nantong University Ethics
Committee. A total of $100 \mu \mathrm{l}$ phosphate-buffered saline (PBS) mixed with $5 \times 10^{6}$ control and transfected cells (SGC7901 transfected with pcDNA3.1B-CDCA3; BGC823 transfected with p-SUPER-sh-1069) were separately and subcutaneously inoculated into each flank of nude mice. The tumor size of inoculated nude mice was monitored and measured every third day following injection. The mice were sacrificed and the subcutaneous tumors were dissected and weighed following 3 weeks. During the experiment, the nude mice were exposed to a natural light-dark cycle at room temperature and a specific-pathogen-free (SPF) environment, and were allowed to feed and drink water ad libitum. Carbon dioxide was used to euthanize the mice and the subcutaneous tumors were dissected out and weighed after 3 weeks. The tumor volume was calculated using the following formula: Tumor volume $=$ length $\mathrm{x}$ width ${ }^{2} \times 0.5$. Care of experimental animals was in accordance with institutional animal care and use committee guidelines.

Flow cytometric analysis. Transfected cells were seeded at a density of $1 \times 10^{5}$ cells/well into 6-well plates, incubated overnight at $37^{\circ} \mathrm{C}$, harvested by trypsinization without EDTA and the cells were washed two times with ice-cold PBS. Following treatment with $75 \%$ ethanol at $4^{\circ} \mathrm{C}$ overnight, the cells were incubated on ice for $1 \mathrm{~h}$. Subsequently, the fixed cells were stained at room temperature for $30 \mathrm{~min}$ with $0.5 \mathrm{ml}$ PBS solution containing $0.2 \mathrm{mM}$ EDTA, $20 \mathrm{mg} / \mathrm{ml}$ of propidium iodide and $0.2 \%$ Triton X-100. The proportion of cells in the $\mathrm{G}_{0} / \mathrm{G}_{1}, \mathrm{~S}$ and $\mathrm{G}_{2} / \mathrm{M}$ phases of the cell cycle was evaluated employing the Beckman Gallios Flow Cytometer (Beckman Coulter, Inc., Brea, CA, USA).

Western blot analysis. A total of $25 \mathrm{mmol} / 1$ Tris- $\mathrm{Cl}(\mathrm{pH} 7.5)$, $5 \mathrm{mmol} / 1 \mathrm{EDTA}, 1 \%$ SDS and $1 \%$ protein lysate with protease inhibitor were used to extract protein, and we determined the protein concentration using a BCA kit. Total cellular proteins (10 $\mu \mathrm{l}$ protein/lane) were separated by SDS-polyacrylamide gel electrophoresis (10\% separation gel and $4 \%$ stacking gel), blotted onto polyvinylidene difluoride (PVDF) membranes, the PVDF membranes were blocked by $5 \%$ skimmed milk, at room temperature for $1 \mathrm{~h}$ and then were incubated with specific primary antibodies at $4^{\circ} \mathrm{C}$ overnight. Following incubation for $1 \mathrm{~h}$ at room temperature with horseradish peroxidase (HRP)-conjugated secondary antibody (dilution 1:2,000; cat. no. Ab205718), each membrane was detected using an enhanced chemiluminescence (ECL) detection system (Pierce Biotechnology, Inc., Rockford, IL, USA) according to the manufacturer's protocol. The inclusion of the primary antibodies used in the present study as follows: Anti-CDCA3 (dilution 1:1,000; cat. no. ab167037), anti-p-RAS (dilution 1:1,000; cat. no. ab214100), anti-t-RAS (dilution 1:5,000; cat. no. ab52939), anti-p-MEK (dilution 1:1,000; cat. no. ab194754), anti-t-MEK (dilution 1:5,000; cat. no. ab178876), anti-p-ERK (dilution 1:1,000; cat. no. ab201015), anti-t-ERK (dilution 1:1,000; cat. no. ab17942), anti-p21Cip1 (dilution 1:1,000; cat. no. ab109520), anti-cyclin D1 (dilution 1:200; cat. no. ab16663), anti-cyclin E (dilution 1:1,000; cat. no. ab33911) and anti- $\beta$-actin (dilution 1:1,000; cat. no. ab8226) antibody (all purchased from Abcam). 
Table I. Association of CDCA3 expression in tumorous tissues with clinicopathological characteristics in GC patients.

\begin{tabular}{|c|c|c|c|c|c|}
\hline \multirow[b]{2}{*}{ Clinicopathologic characteristics } & \multirow[b]{2}{*}{$\mathrm{n}$} & \multicolumn{2}{|c|}{ CDCA3 } & \multirow[b]{2}{*}{ Pearson $\chi^{2}$} & \multirow[b]{2}{*}{ P-value } \\
\hline & & Low or no expression & High expression & & \\
\hline Total & 150 & $64(42.67)$ & $86(57.33)$ & & \\
\hline Sex & & & & 0.492 & 0.483 \\
\hline Male & 96 & $43(44.79)$ & $53(55.21)$ & & \\
\hline Female & 54 & $21(38.89)$ & $33(61.11)$ & & \\
\hline Age at diagnosis (years) & & & & 0.060 & 0.807 \\
\hline$\leq 60$ & 65 & $27(41.54)$ & $38(58.46)$ & & \\
\hline$>60$ & 85 & $37(43.53)$ & $48(56.47)$ & & \\
\hline Tumor size $(\mathrm{cm})$ & & & & 6.968 & $0.008^{\mathrm{a}}$ \\
\hline$<3$ & 46 & $27(58.70)$ & $19(41.30)$ & & \\
\hline$\geq 3$ & 104 & $37(35.58)$ & $67(64.42)$ & & \\
\hline Location & & & & 2.194 & 0.334 \\
\hline Lower & 102 & $45(44.12)$ & $57(52.88)$ & & \\
\hline Middle & 31 & $10(32.26)$ & $21(67.74)$ & & \\
\hline Upper & 17 & $9(52.94)$ & $8(47.06)$ & & \\
\hline Differentiation & & & & 8.012 & $0.005^{\mathrm{a}}$ \\
\hline Low grade & 90 & $30(33.33)$ & $60(66.67)$ & & \\
\hline Middle and high grade & 60 & $34(56.67)$ & $26(43.33)$ & & \\
\hline Primary tumor & & & & 7.492 & $0.024^{\mathrm{a}}$ \\
\hline $\mathrm{T} 1$ & 33 & $19(57.58)$ & $14(42.42)$ & & \\
\hline $\mathrm{T} 2$ & 30 & $16(53.33)$ & $14(46.67)$ & & \\
\hline $\mathrm{T} 3+\mathrm{T} 4$ & 87 & $29(33.33)$ & $58(66.67)$ & & \\
\hline Lauren type & & & & 0.109 & 0.741 \\
\hline Intestinal & 96 & $40(41.67)$ & $56(58.33)$ & & \\
\hline Diffuse/other & 54 & $24(44.44)$ & $30(55.56)$ & & \\
\hline Lymph node metastasis & & & & 13.252 & $0.001^{\mathrm{a}}$ \\
\hline $\mathrm{N}_{0}$ & 71 & $40(56.34)$ & $31(43.66)$ & & \\
\hline $\mathrm{N}_{1}$ & 19 & $9(47.37)$ & $10(52.63)$ & & \\
\hline $\mathrm{N}_{2}+\mathrm{N}_{3}$ & 60 & $15(25.00)$ & $45(75.00)$ & & \\
\hline Stage grouping with TNM & & & & 23.720 & $0.001^{\mathrm{a}}$ \\
\hline I & 50 & $29(58.00)$ & $21(42.00)$ & & \\
\hline II & 33 & $21(63.64)$ & $12(36.36)$ & & \\
\hline $\mathrm{III}+\mathrm{IV}$ & 67 & $14(20.90)$ & $53(79.10)$ & & \\
\hline
\end{tabular}

${ }^{\mathrm{a}} \mathrm{P}<0.05$. CDCA3, cell division cycle-associated 3; GC, gastric cancer; TNM, tumor-node-metastasis.

Follow-up of patients. GC tissues and paired normal adjacent mucosa tissues were derived from 150 patients with GC who had undergone surgeries at the Affiliated Hospital of Nantong University between April 2010 and March 2011. The lump and the regional lymph nodes were radically dissected and the edge of the resection was tumor-free, which was deemed to be curatively resected. Patients with GC with distant metastasis were not included in the present study. Follow-up visits of 150 GC patients ranged from April 2011 to March 2016 and the specified clinicopathological features of the 150 patients with GC are listed Table I.
Statistical analysis. The study data were analyzed using SPSS 19.0 and GraphPad Prism 5.0 software (GraphPad Software, Inc., La Jolla, CA, USA). A two-tailed Student's t-test was employed to analyze differences between 2 groups. Multiple comparisons between groups was performed using analysis of variance (ANOVA) followed by Student-Newman-Keuls test. The $\chi^{2}$ test was employed to determine categorical data. The Kaplan-Meier method was employed to estimate survival rates and the log-rank test was used to compare the significance between survival times. A Univariate Cox regression model was used to investigate factors of prognostic significance and 
Table II. Univariate and multivariate analysis of prognostic factors of the 5-year overall survival in GC patients.

\begin{tabular}{|c|c|c|c|c|c|c|}
\hline \multirow[b]{2}{*}{ Characteristics } & \multicolumn{3}{|c|}{ Univariate analysis } & \multicolumn{3}{|c|}{ Multivariate analysis } \\
\hline & HR & P-value & $95 \% \mathrm{CI}$ & HR & $\mathrm{P}$-value & $95 \% \mathrm{CI}$ \\
\hline $\begin{array}{l}\text { CDCA3 expression } \\
\text { High vs. low and none }\end{array}$ & 4.265 & $<0.00^{\mathrm{a}}$ & $2.316-7.857$ & 2.719 & $0.003^{\mathrm{a}}$ & $1.396-5.296$ \\
\hline $\begin{array}{l}\text { Sex } \\
\text { Male vs. female }\end{array}$ & 0.823 & 0.447 & $0.523-1.250$ & & & \\
\hline $\begin{array}{l}\text { Age (years) } \\
\leq 60 \text { vs. }>60\end{array}$ & 0.883 & 0.619 & $0.498-1.360$ & & & \\
\hline $\begin{array}{l}\text { Location } \\
\text { Lower vs. middle vs. upper }\end{array}$ & 0.946 & 0.748 & $0.673-1.329$ & & & \\
\hline $\begin{array}{l}\text { Tumor size }(\mathrm{cm}) \\
<3 \text { vs. } \geq 3\end{array}$ & 2.686 & $0.003^{\mathrm{a}}$ & $1.402-5.148$ & 1.044 & 0.910 & $0.496-2.198$ \\
\hline $\begin{array}{l}\text { Differentiation } \\
\text { Low vs. middle and high grade vs. others }\end{array}$ & 0.416 & $0.005^{\mathrm{a}}$ & $0.225-0.767$ & 0.830 & 0.572 & $0.435-1.584$ \\
\hline $\begin{array}{l}\text { Primary tumor } \\
\text { T1 vs. T2 vs. T3+T4 }\end{array}$ & 2.606 & $<0.001^{\mathrm{a}}$ & $1.693-4.010$ & 0.799 & 0.504 & $0.413-1.544$ \\
\hline $\begin{array}{l}\text { Lauren type } \\
\text { Intestinal vs. diffuse/other }\end{array}$ & 0.955 & 0.872 & $0.542-1.681$ & & & \\
\hline $\begin{array}{l}\text { Lymph node metastasis } \\
\text { N0 vs. N1 vs. N2+N3 }\end{array}$ & 2.035 & $<0.001^{\mathrm{a}}$ & $1.649-2.510$ & 1.248 & 0.126 & $0.939-1.658$ \\
\hline $\begin{array}{l}\text { TNM stage } \\
\text { I vs. II vs. III+IV }\end{array}$ & 3.716 & $<0.001^{\mathrm{a}}$ & $2.460-5.614$ & 2.462 & $0.008^{\mathrm{a}}$ & $1.263-4.800$ \\
\hline
\end{tabular}

${ }^{\text {a }} \mathrm{P}<0.05$. GC, gastric cancer; CDCA3, cell division cycle-associated 3; HR, hazard ratio; CI, confidence interval; TNM, tumor-node-metastasis .

then the factors were further investigated using a multivariate Cox regression model. Quantitative results were expressed as the mean $\pm \mathrm{SD}$. $\mathrm{P}<0.05$ was considered to indicate a statistically significant difference.

\section{Results}

CDCA3 expression in GC tissues and GC cell lines. RT-qPCR was performed to assess the CDCA 3 mRNA expression levels in GC and adjacent non-cancerous tissues from 150 patients. The results indicated that CDCA 3 mRNA was increased in 106 (70.7\%) of the $150 \mathrm{GC}$ specimens compared with the matched normal gastric tissues (Fig. 1A). Furthermore, the expression of CDCA3 in a normal human gastric epithelial cell line (GES-1) and diverse human GC cell lines was also detected by qRT-PCR analysis. Our results indicated that CDCA3 expression was markedly upregulated in all GC-derived cell lines (BGC823, AGS, MKN45, MKN28 and SGC7901) compared with GES-1 (Fig. 1B). IHC analysis was performed to evaluate CDCA3 protein expression in GC specimens and paired normal gastric tissues in the same 150 matched samples. Of these specimens, $86 / 150(57.3 \%)$ of cancerous specimens exhibited high CDCA3 expression, whereas 43/150 (28.7\%) of normal gastric tissues exhibited high CDCA3 expression (Fig. 1C). The collective results indicated an aberrant upregulation of CDCA3 in GC.
Clinical significance of $C D C A 3$ in $G C$ patients. To access the clinical significance of ectopic CDCA3 expression in GC progression, the relationship between CDCA3 expression and clinicopathological features were evaluated. The patients with GC were split into 2 groups according to the results obtained by the results of IHC analysis for CDCA3: A high-CDCA3 expression group and a low-CDCA 3 expression group, and associations between high CDCA3 expression and tumor size $(\mathrm{P}=0.008)$, differentiation $(\mathrm{P}=0.005)$, primary tumor $(\mathrm{P}=0.024)$, lymph node metastasis $(\mathrm{P}=0.001)$ and TNM stage $(\mathrm{P}=0.001)$ were identified (Table I). Univariate analysis was applied to investigate all relevant features, and high CDCA3 expression $(\mathrm{P}<0.001)$, along with tumor size $(\mathrm{P}=0.003)$, tumor differentiation $(\mathrm{P}=0.005)$, primary tumor $(\mathrm{P}<0.001)$, lymph node metastasis $(\mathrm{P}<0.001)$ and tumor TNM stage $(\mathrm{P}<0.001)$, were identified to be significantly associated with patient survival. Multivariate regression analysis was subsequently employed to further confirm that CDCA3 expression $(\mathrm{P}=0.003)$ and TNM stage $(\mathrm{P}=0.008)$ were independent prognostic indicators in GC (Table II).

Increased expression of CDCA3 predicts poor prognosis in patients with $G C$. A total of 150 patients were enrolled in the present study. At the last point of follow-up 64 patients had died, of whom 51 exhibited high CDCA3 expression, and 13 exhibited low CDCA3 expression. Among the survivors, 
A

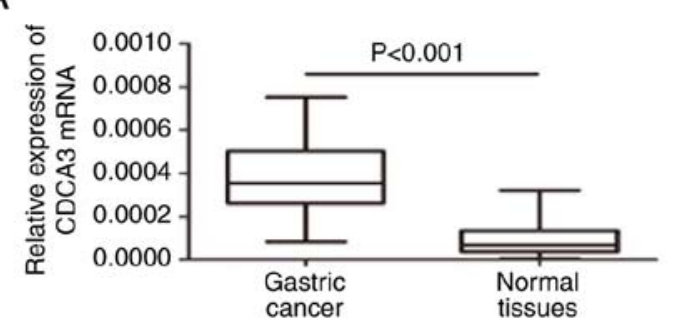

C
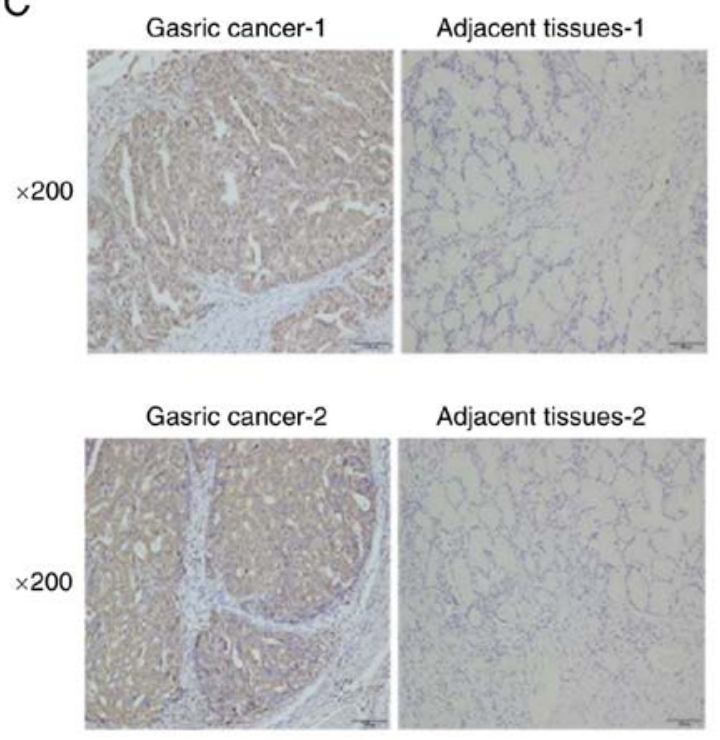

B
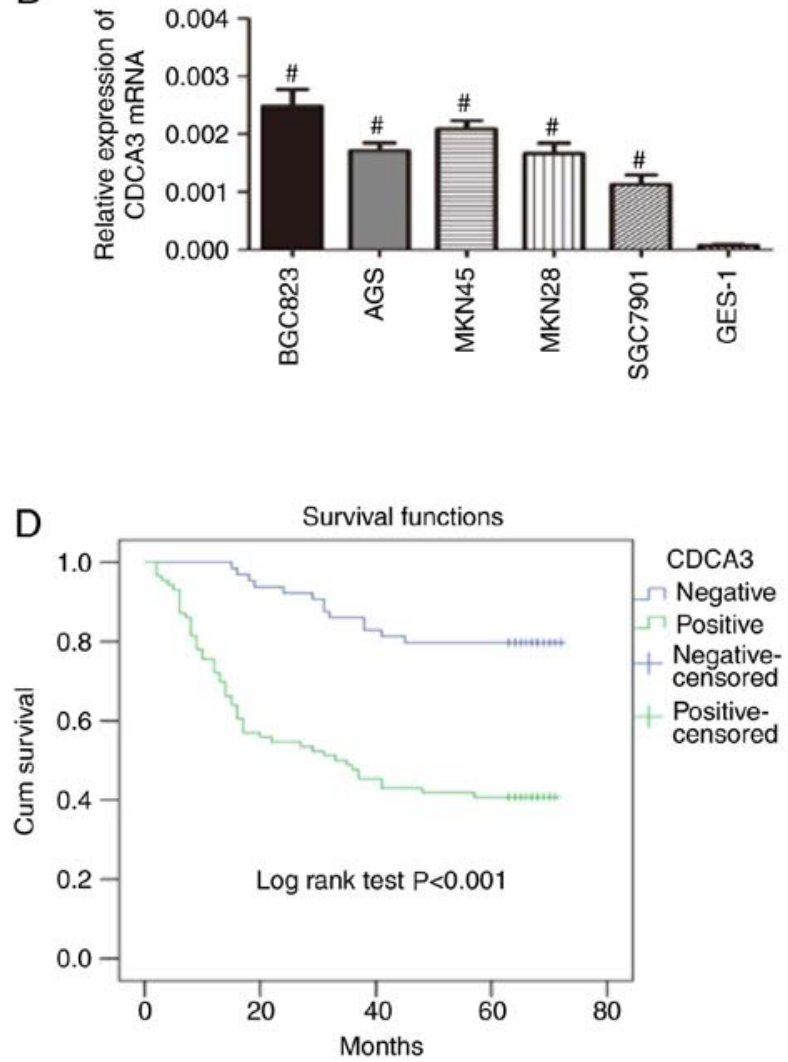

Figure 1. CDCA3 overexpression is related with poor clinical prognosis in GC patients. (A) CDCA3 expression in 150 pairs of GC and normal tissues. (B) The expression of CDCA3 mRNA in GC cell lines and normal human gastric epithelial cells was evaluated using qRT-PCR. ${ }^{~} \mathrm{P}<0.05$ compared to GES-1. (C) Representative images of IHC staining for CDCA3 protein in GC specimens. Magnification, x200. (D) Kaplan-Meier overall survival curve of GC patients based on CDCA3 expression. CDCA3, cell division cycle-associated 3; GC, gastric cancer; IHC, immunohistochemical.

the data indicated that 35 patients exhibited high expression levels of CDCA3 and 51 exhibited low CDCA3 expression. Furthermore, the results indicated that the overall survival rate over 5 years for the high CDCA3 group was $40.7 \%$, whereas it was $79.7 \%$ for the low CDCA3 group (Fig. 1D).

Overexpression of CDCA3 promotes cell proliferation and induces the cell cycle transition from the $G_{0} / G_{1}$ to the $S$ phase. To explore the role of CDCA3 in the tumor growth of GC, CDCA3 overexpression was established, employing pcDNA3.1B-CDCA3 in the GC cell line SGC7901. Western blotting was used to determine the transfection efficiency of CDCA3 protein expression in the SGC7901 cell line at $48 \mathrm{~h}$ following transfection. The results indicated that pcDNA3.1B-CDCA3 effectively upregulated CDCA3 expression in the SGC7901 cell line (Fig. 2A). The ectopic expression of CDCA3 significantly promoted cell growth compared with SGC7901 cells that were transfected with an empty vector (Fig. 2B). In conjunction with this, the number of colonies that formed in CDCA3-transfected SGC7901 cells were significantly increased compared with the empty vector-transfected SGC7901 cells $(\mathrm{P}<0.05)$ (Fig. 2C). To further evaluate the mechanism by which CDCA3 promotes cell proliferation, flow cytometry was used to determine the effect of CDCA3 on cell cycle distribution at $24 \mathrm{~h}$ following transfection. As illustrated in Fig. 2D the ectopic expression of CDCA3 in SGC7901 cells successfully accomplished cycle transition from the $G_{0} / G_{1}$ to the $S$ phase compared with the empty vector-transfected SGC7901 and the percentage of cells in the $\mathrm{S}$ phase increased by $12.52 \%$ in the CDCA3-transfected SGC7901 cells $(\mathrm{P}<0.05)$ at $24 \mathrm{~h}$. These results demonstrated that CDCA3 is important for the promotion of GC cell growth in vitro.

CDCA3 knockdown inhibits cell proliferation and induces cell cycle arrest in the $G_{0} / G_{1}$ phase. shRNA-1069 derived from recombinant pSUPER was chemically synthesized to knockdown endogenous CDCA3, concurrently as sh-NC in the BGC823 cell line. Western blotting was used to determine the transfection efficiency of CDCA3 protein expression in the BGC 823 cell line at $48 \mathrm{~h}$ following transfection. The results indicated that p-SUPER-sh-1069 effectively downregulated CDCA3 expression in the BGC823 cell line (Fig. 3A). The downregulated expression of CDCA3 significantly suppressed cell growth compared with sh-NC transfected cells $(\mathrm{P}<0.05)$ (Fig. 3B). In keeping with this, the number of colonies that formed in BGC 823 cells transfected with p-SUPER-shRNA-CDCA3 were significantly inhibited in comparison with BGC823 cells transfected with sh-NC $(\mathrm{P}<0.05)$ (Fig. 3C). To further evaluate the effect 
A

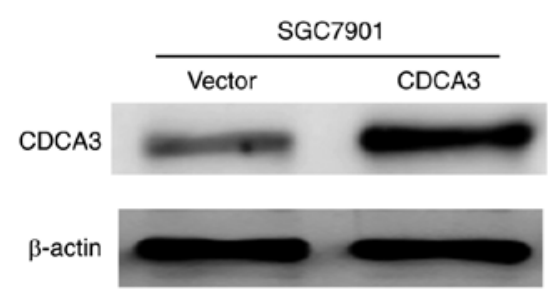

C

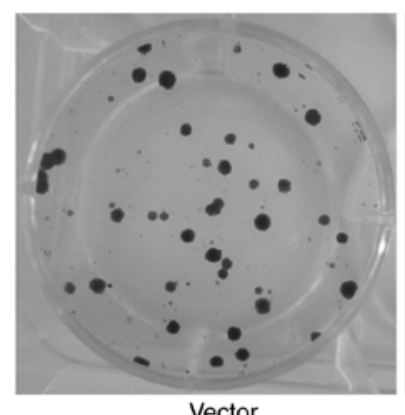

Vector

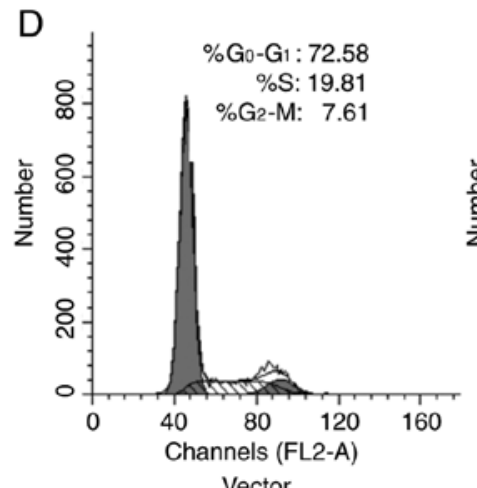

Vector

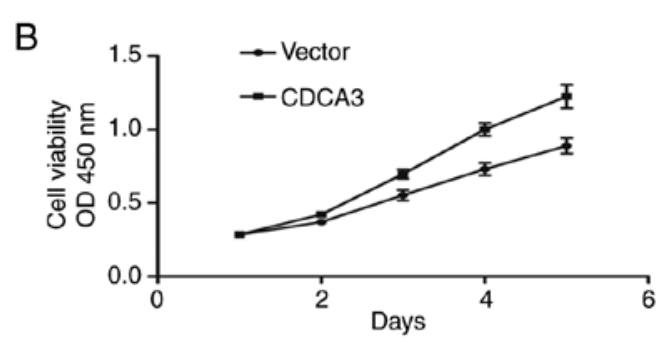

GC7901
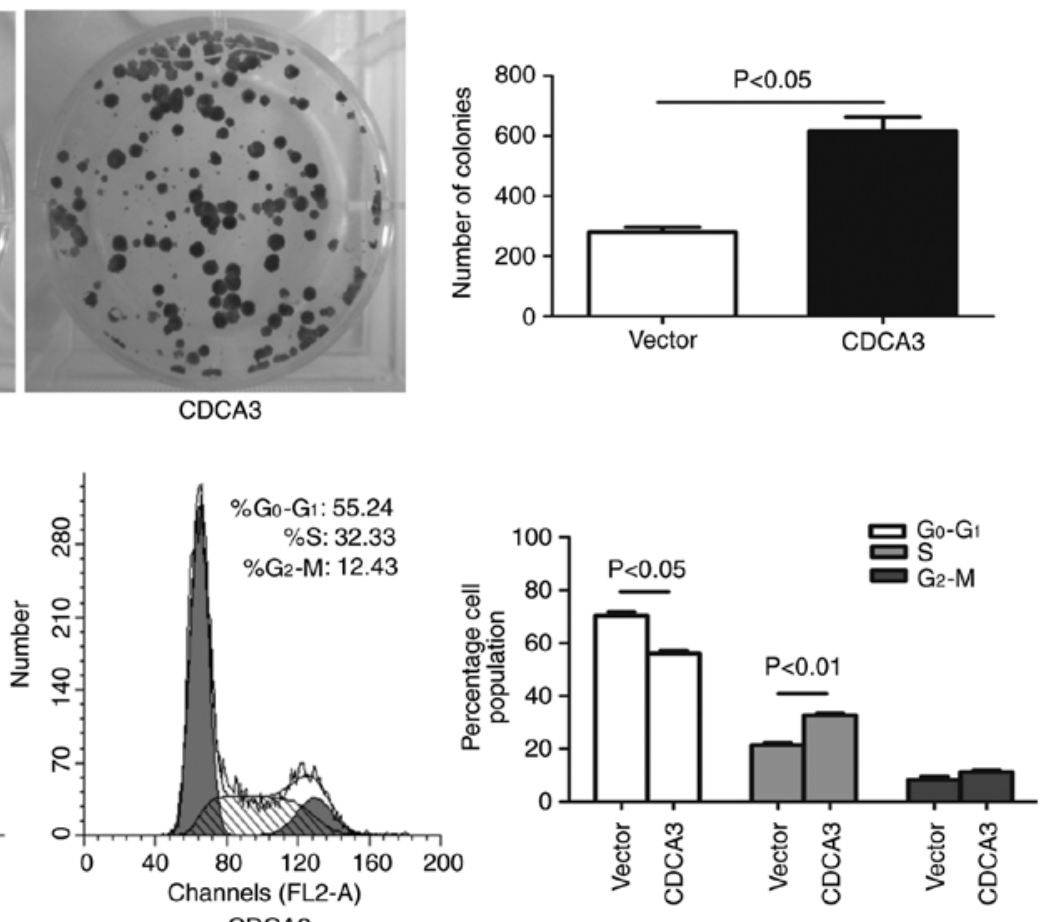

Figure 2. Effect of CDCA3 overexpression on the growth of SGC7901 cells in vitro. (A) Western blot analyses of overexpression efficiency in SGC7901 cells (B) Cellular proliferation of treated SGC7901 cells was evaluated using a CCK-8 cell proliferation assay at the indicated time-points. P<0.05. (C) Representative images of colony formation in empty vector-transfected and CDCA3-transfected SGC7901 cells. (D) CDCA3 overexpression promotesd SGC7901 cells to enter the $\mathrm{S}$ phase from the $\mathrm{G}_{0} / \mathrm{G}_{1}$ phase. CDCA3, cell division cycle-associated 3; CCK-8, Cell Counting Kit-8.

of downregulation of CDCA3 on cell proliferation, flow cytometry was used to determine cell cycle distribution $24 \mathrm{~h}$ following transfection. As illustrated in Fig. 3D, knockdown of CDCA3 was associated with cell cycle arrest at the G0/G1 stage, as there was an increase of the percentage of cells in the $\mathrm{G}_{0} / \mathrm{G}_{1}$ phase in the $\mathrm{p}$-SUPER-sh-CDCA3 transfected group by $15.33 \%$ compared to the sh-NC group $(\mathrm{P}<0.05)$ at $24 \mathrm{~h}$.

Differential expression of CDCA3 affects tumorigenesis and tumor burden. To explore the effect of CDCA3 expression on tumorigenic potential of GC cell lines in vivo, the present study performed a nude mouse xenograft assay. SGC7901 cells overexpressing CDCA3 and BGC823 cells with downregulated CDCA3 expression were injected subcutaneously into the flank of nude mice. CDCA3-overexpressing cells significantly promoted tumor growth in terms of increased capacity for tumorigenesis compared with the control group (Fig. 4A, C and E). Furthermore, the present study also demonstrated that CDCA3 silencing substantially inhibited tumor growth in terms of decreased capacity for tumorigenesis in comparison with the negative controls (Fig. 4B, D and F). These data indicated that the in vivo and in vitro investigations had the same varying trend regarding cell proliferation, and indicated that CDCA3 may function as an accelerator of tumorigenicity.

CDCA3 promotes GC progression by activating the Ras signaling pathway. To further explore the signaling pathway by which CDCA3 enhances the progression of GC, western blotting was performed to determine potential CDCA3-regulated molecules. As illustrated in Fig. 5, the levels of p-Ras, p-MEK, p-ERK, cyclin D1 and cyclin E were increased; however, CDKI (p21Cip1) was decreased in the CDCA3-overexpressing SGC7901 cells when compared with the control group. However, no difference in the t-Ras, $t-M E K$ and $t-E R K$ protein levels were observed between the 2 groups.

The levels of p-Ras, p-MEK, p-ERK, cyclin D1 and cyclin E were decreased, however CDKI (p21Cip1) was increased in CDCA3-downregulated BGC823 cells compared with the control group. Similarly, the expression of t-Ras, t-MEK and t-ERK protein levels were significantly unvaried between the 2 groups (Fig. 5). Collectively, this data demonstrated that the Ras signaling pathway may participate in CDCA3-mediated GC progression. 
A

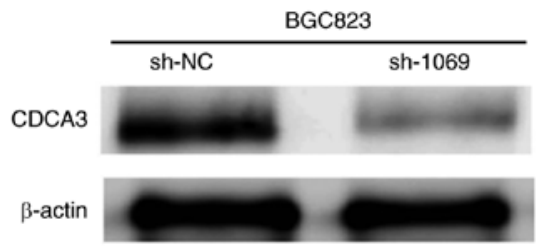

C

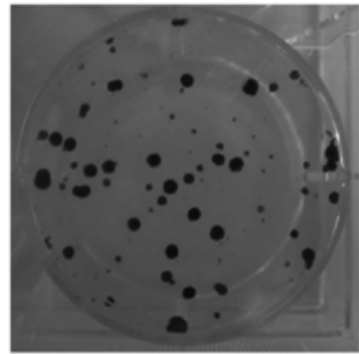

sh-NC

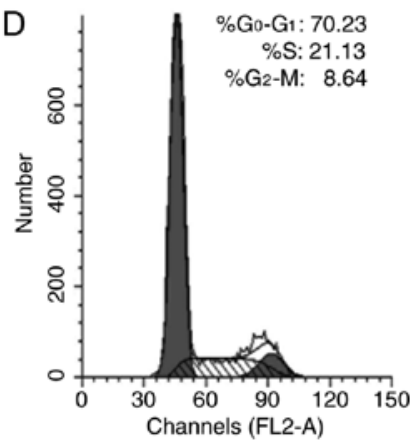

sh-NC

BGC823
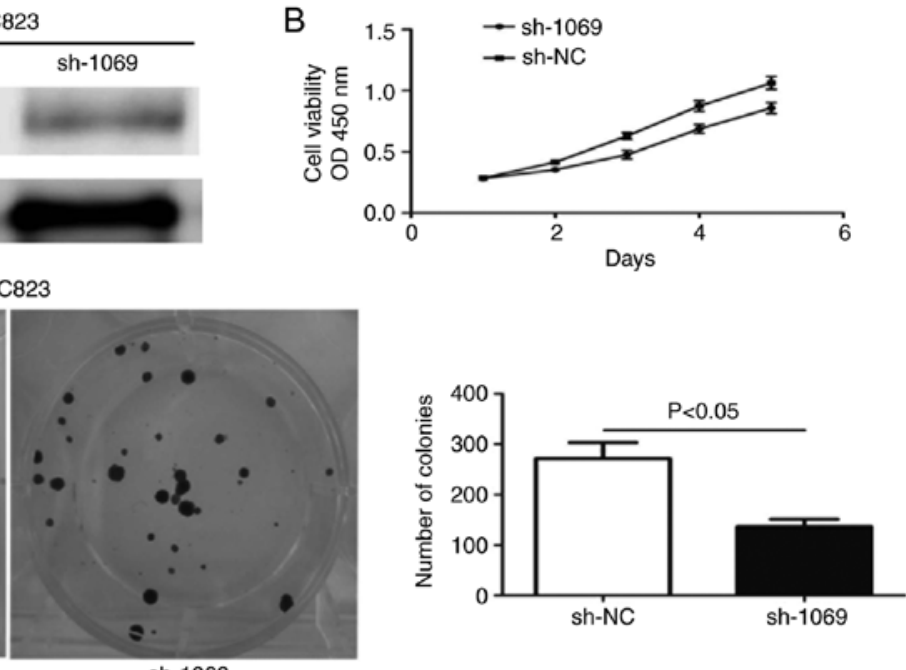

Figure 3. Effect of CDCA3 knockdown on the growth of BGC823 cells in vitro. (A) Western blot analyses of knockdown efficiency in BGC823 cells (B) Cellular proliferation of treated BGC823 cells was evaluated using a CCK- 8 cell proliferation assay at the indicated time-points. $\mathrm{P}<0.05$. (C) Representative images of colony formation in CDCA3-depleted or control BGC823 cells. (D) Knockdown of CDCA3 blocked the cell cycle at the $\mathrm{G}_{0} / \mathrm{G}_{1}$ phase in BGC823 cells. CDCA3, cell division cycle-associated 3; CCK-8, Cell Counting Kit-8.

A

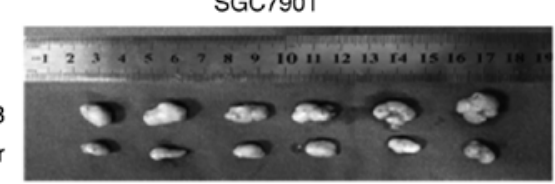

$\mathrm{E}$

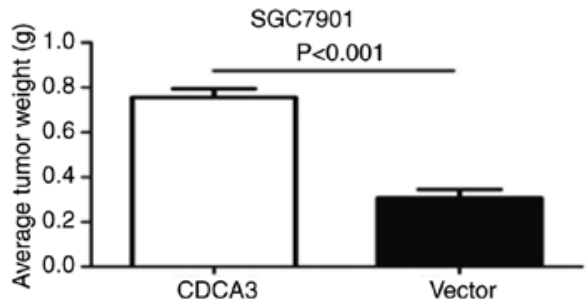

C

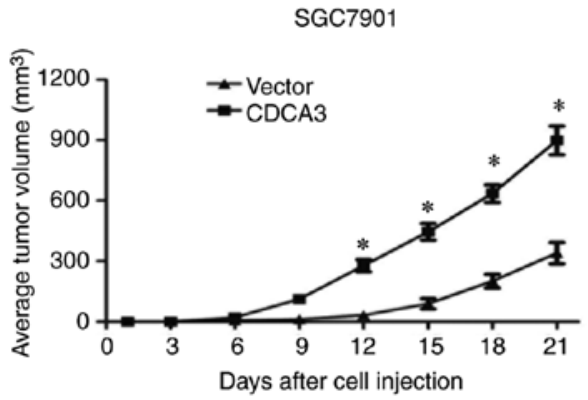

CDCA3

$$
\text { Vecto }
$$

B

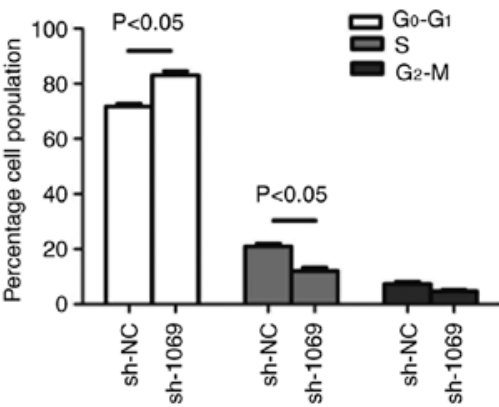

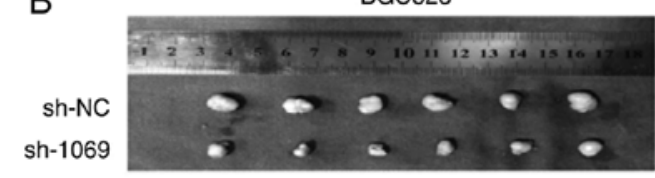

D BGC823

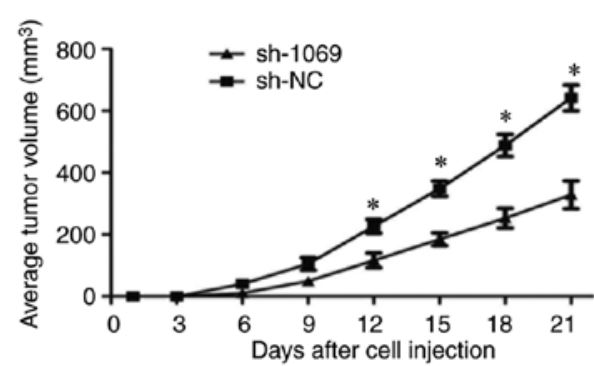

$\mathrm{F}$

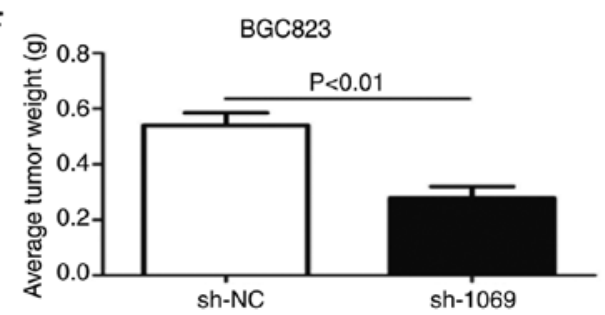

Figure 4. Effects of CDCA3 on xenograft tumor growth of GC cells in vivo. (A and B) Representative image of tumors developed in the subcutaneous implanted model. (C and D) The tumor growth curves are summarized in the line chart. " $\mathrm{P}<0.05$. (E and F) A statistical plot of average tumor weights in the subcutaneous implanted model. The graphs represent the mean $\pm \mathrm{SD} ; \mathrm{P}<0.01, \mathrm{P}<0.001$. CDCA3, cell division cycle-associated 3; GC, gastric cancer. 


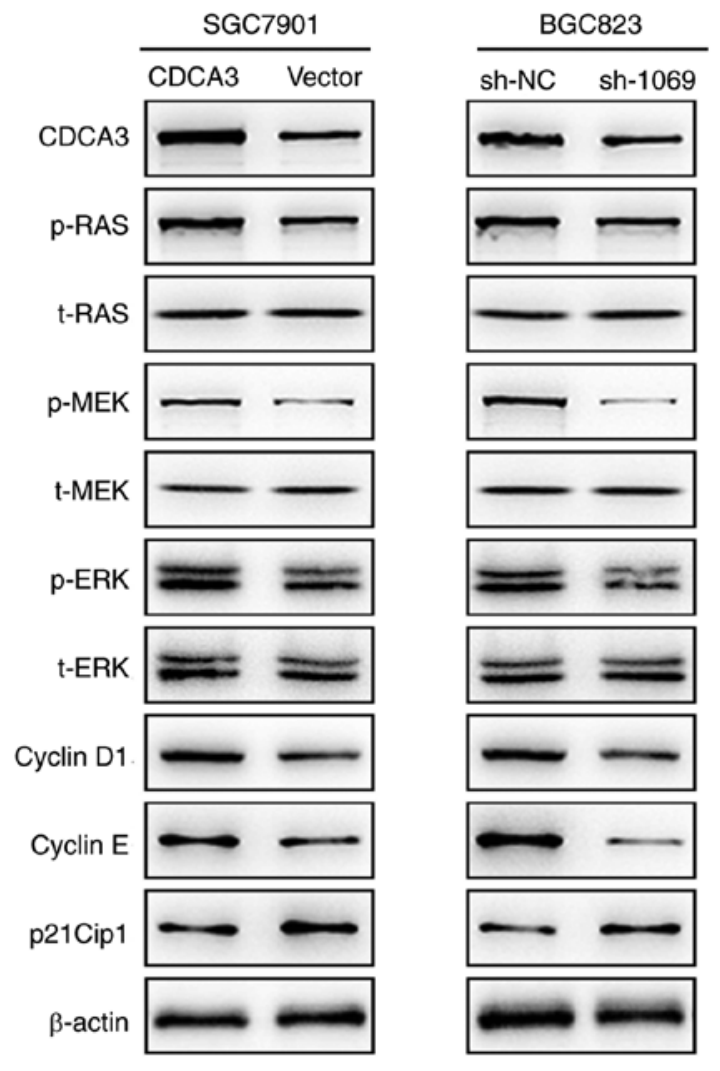

Figure 5. CDCA3 exerts a proliferative effect via the Ras signaling pathway. The protein expression levels of CDCA3, cyclin D1, cyclin E, p-Ras, t-Ras, p-MEK, t-MEK, p-ERK, t-ERK, and CDKI (p21Cip1) were determined in the indicated cells. $\beta$-actin was used as the loading control. CDCA3, cell division cycle-associated 3.

\section{Discussion}

The present study demonstrated that CDCA3 was highly expressed in GC tissues compared with peritumoral gastric tissue by RT-qPCR and IHC analysis. In addition, high levels of CDCA3 expression were associated with tumor size, differentiation and TNM stage in GC. Notably, Cox proportional hazard regression analysis revealed that CDCA3 could act as an independent unfavorable biomarker to predict the outcome of patients with GC. Through in vitro and in vivo analyses, the present study also demonstrated that CDCA 3 could markedly influence the proliferation of GC cells. Collectively, these results indicated that CDCA3 had a critical role in GC development and progression.

Recently, it has been revealed that the upregulation of CDCA3 is closely linked to human cancers, such as oral and prostate cancer, which strengthens the significance of CDCA3 as a valuable prognostic marker in clinical treatment $(17,20)$. However, the precise molecular mechanisms of CDCA3 in GC development are still unclear. Previous studies have demonstrated that the RAS-GTP enzyme-activated protein DAB2IP can combine with DAB2 to produce a specific protein complex, which can exert a negative regulatory effect on the ERK/MAPK signaling pathway (23-25). Research has been performed in recent years demonstrating that there is a low expression of DAB2IP in numerous malignant tumors, including prostate and breast cancer $(26,27)$. Furthermore, additional studies have demonstrated that the downregulation of endogenous DAB2IP expression can enhance the proliferation of prostate and breast cancer $(28,29)$. Such downregulation can promote the transfer of epithelial cells from epithelium to mesenchymal, a critical step of tumor metastasis (30-32). The ERK/MAPK signaling pathway is a cascade process composed of receptor tyrosine kinase activated by small GTP protein as well as plasmosin $(33,34)$. The crux of activation is to make RAS experience guanine-nucleotide exchange and further progress into the activated form RAS-GTP $(35,36)$. Located in the downstream of RAS, ERK is principally activated by growth factor receptor with the involvement of the RAS protein (37). Typically, ERK is located within the cytoplasm $(37,38)$. Upon being activated by phosphorylation, ERK will rapidly pass through the nuclear membrane, and regulate the activation of some intra-nuclear transcription factors, which may further regulate the transcription of their respective targeted genes, trigger the alteration of specific protein expression and activation, eventually regulate cell metabolism and function, and influence the specific biological function of cells (35).

A train of biological functional experiments of CDCA3 in vitro and in vivo, in the present study, indicated that CDCA3 possesses a tumor-stimulative function in GC. The overexpression of CDCA3 could promote cell proliferation in the SGC7901 cell line in vitro and function as a promotor of tumorigenicity in vivo; while the opposite phenomenon occured with knockdown of CDCA3. The data obtained by the present study strongly suggests that CDCA3 functions as an oncogene in GC. To address the underlying molecular mechanism by which CDCA3 regulates cell proliferation, the effect of differential CDCA3 expression on the variation in the protein expression profile and cell cycle progression was explored. The results of the present study indicated that the changes in cell proliferation were due to the blocking of the cell cycle at the $\mathrm{G}_{0} / \mathrm{G}_{1}$ phase or entering the $S$ phase from the $\mathrm{G}_{0} / \mathrm{G}_{1}$ phase with overexpression as a result of the knockdown of CDCA3 expression-mediated Ras signaling pathway-related proteins.

Therefore, we hypothesize that, in GC cells, overexpression of CDCA3 resulted in the continuous activation of Ras, and eventually induced the aberrant activation of the ERK/MAPK signaling pathway, which resulted in the development of GC progression. However, the detailed interactions between CDCA 3 and the ERK/MAPK signaling pathway-related proteins remain to be evaluated.

In summary, to the best of our knowledge, the present study is the first to confirm that CDCA3 was upregulated in GC tissues and cell lines and was associated with an unfavorable prognosis in patients with GC. CDCA3 expression was associated with the promotion of cell proliferation in GC cell lines. Furthermore, evidence was presented to suggest that CDCA3 mediated the Ras/ERK/MAPK axis to promote GC cell proliferation. Collectively, these findings indicate that the ectopic expression of CDCA3 may serve as a potential diagnostic and prognostic marker in the treatment of GC.

\section{Acknowledgements}

Not applicable. 


\section{Funding}

This study were supported by the National Natural Science Foundations for Young Scientists of China (grant no. 81502053).

\section{Availability of data and materials}

The datasets used during the present study are available from the corresponding author upon reasonable request.

\section{Authors' contributions}

QN conceived and designed the experiments. YZ, WY and WC carried out the experiments. PC and LB participated in the statistical analysis and interpretation of data. QN and YZ wrote this manuscript. All authors read and approved the manuscript and agree to be accountable for all aspects of the research in ensuring that the accuracy or integrity of any part of the work are appropriately investigated and resolved.

\section{Ethics approval and consent to participate}

The present study was approved by the Ethics Committee of the Affiliated Hospital of Nantong University. All procedures performed in this study were in accordance with the 1964 Helsinki Declaration and its later amendments. Written informed consent was obtained from all patients included in the study.

\section{Patient consent for publication}

Not applicable.

\section{Competing interests}

The authors state that they have no competing interests.

\section{References}

1. Tao J, Zhi X, Zhang X, Fu M, Huang H, Fan Y, Guan W and Zou C: miR-27b-3p suppresses cell proliferation through targeting receptor tyrosine kinase like orphan receptor 1 in gastric cancer. J Exp Clin Cancer Res 34: 139, 2015.

2. Jemal A, Bray F, Center MM, Ferlay J, Ward E and Forman D: Global cancer statistics. CA Cancer J Clin 61: 69-90, 2011.

3. Lee YY and Derakhshan MH: Environmental and lifestyle risk factors of gastric cancer. Arch Iran Med 16: 358-365, 2013.

4. Ferlay J, Soerjomataram I, Dikshit R, Eser S, Mathers C, Rebelo M, Parkin DM, Forman D and Bray F: Cancer incidence and mortality worldwide: Sources, methods and major patterns in GLOBOCAN 2012. Int J Cancer 136: E359-E386, 2015.

5. Cheng XJ, Lin JC and Tu SP: Etiology and prevention of gastric cancer. Gastrointest Tumors 3: 25-36, 2016.

6. Hartgrink HH, Jansen EP, van Grieken NC and van de Velde CJ: Gastric cancer. Lancet 374: 477-490, 2009.

7. Pennathur A, Farkas A, Krasinskas AM, Ferson PF, Gooding WE, Gibson MK, Schuchert MJ, Landreneau RJ and Luketich JD: Esophagectomy for T1 esophageal cancer: Outcomes in 100 patients and implications for endoscopic therapy. Ann Thorac Surg 87: 1048-1055, 2009.

8. GASTRIC (Global Advanced/Adjuvant Stomach Tumor Research International Collaboration) Group; Paoletti X, Oba K, Burzykowski T, Michiels S, Ohashi Y, Pignon JP, Rougier P, Sakamoto J, Sargent D, et al: Benefit of adjuvant chemotherapy for resectable gastric cancer: A meta-analysis. JAMA 303: $1729-1737,2010$
9. Ahn JY, Hwang HS, Park YS, Kim HR, Jung HY, Kim JH, Lee SE and Kim MA: Endoscopic and pathologic findings associated with clinical outcomes of melanoma in the upper gastrointestinal tract. Ann Surg Oncol 21: 2532-2539, 2014.

10. Smith A, Simanski S, Fallahi M and Ayad NG: Redundant ubiquitin ligase activities regulate weel degradation and mitotic entry. Cell Cycle 6: 2795-2759, 2007.

11. Yoshida K: Cell-cycle-dependent regulation of the human and mouse Tome-1 promoters. FEBS Lett 579: 1488-1492, 2005.

12. Lim HH and Surana U: Tome-1, wee1, and the onset of mitosis: Coupled destruction for timely entry. Mol Cell 11: 845-546, 2003.

13. Kim YJ and Bahk YY: A study of substrate specificity for a CTD phosphatase, SCP1, by proteomic screening of binding partners. Biochem Biophys Res Commun 448: 189-194, 2014.

14. Zheng N, Schulman BA, Song L, Miller JJ, Jeffrey PD, Wang P, Chu C, Koepp DM, Elledge SJ, Pagano M, et al: Structure of the Cul1-Rbx1-Skp1-F box ${ }^{\text {Skp2 }}$ SCF ubiquitin ligase complex. Nature 416: 703-709, 2002.

15. Itzel T, Scholz P, Maass T, Krupp M, Marquardt JU, Strand S, Becker D, Staib F, Binder H, Roessler S, et al: Translating bioinformatics in oncology: Guilt-by-profiling analysis and identification of KIF18B and CDCA3 as novel driver genes in carcinogenesis. Bioinformatics 31: 216-224, 2015.

16. Adams MN, Burgess JT, He Y, Gately K, Snell C, Zhang SD, Hooper JD, Richard DJ and O'Byrne KJ: Expression of CDCA3 is a prognostic biomarker and potential therapeutic target in non-small cell lung cancer. J Thorac Oncol 12: 1071-1084, 2017.

17. Chen J, Zhu S, Jiang N, Shang Z, Quan C and Niu Y: HoxB3 promotes prostate cancer cell progression by transactivating CDCA3. Cancer Lett 330: 217-224, 2013.

18. Hu Q, Fu J, Luo B, Huang M, Guo W, Lin Y, Xie X and Xiao S: OY-TES-1 may regulate the malignant behavior of liver cancer via NANOG, CD9, CCND2 and CDCA3: A bioinformatic analysis combine with RNAi and oligonucleotide microarray. Oncol Rep 33: 1965-1975, 2015.

19. Pérez-Peña J, Alcaraz-Sanabria A, Nieto-Jiménez C, Páez R, Corrales-Sánchez V, Serrano-Oviedo L, Wali VB, Patwardhan GA, Amir E, Győrffy B, et al: Mitotic read-out genes confer poor outcome in luminal A breast cancer tumors. Oncotarget 8: 21733-21740, 2017.

20. Uchida F, Uzawa K, Kasamatsu A, Takatori H, Sakamoto Y, Ogawara K, Shiiba M, Tanzawa $\mathrm{H}$ and Bukawa $\mathrm{H}$ : Overexpression of cell cycle regulator CDCA3 promotes oral cancer progression by enhancing cell proliferation with prevention of G1 phase arrest. BMC Cancer 12: 321, 2012.

21. O'Byrne K, Adams M, Burgess J and Richard D: 24P CDCA3 regulates the cell cycle and modulates cisplatin sensitivity in non-small cell lung cancer. J Thorac Oncol 11 (Suppl): S65, 2016.

22. Su P, Wen S, Zhang Y, Li Y, Xu Y, Zhu Y, Lv H, Zhang F, Wang $M$ and Tian Z: Identification of the key genes and pathways in esophageal carcinoma. Gastroenterol Res Pract 2016: 2968106, 2016

23. Zhou J and Hsieh JT: The inhibitory role of DOC-2/DAB2 in growth factor receptor-mediated signal cascade. DOC-2/DAB2-mediated inhibition of ERK phosphorylation via binding to Grb2. J Biol Chem 276: 27793-27798, 2001.

24. Wang Z, Tseng CP, Pong RC, Chen H, McConnell JD, Navone N and Hsieh JT: The mechanism of growth-inhibitory effect of DOC-2/DAB2 in prostate cancer. Characterization of a novel GTPase-activating protein associated with N-terminal domain of DOC-2/DAB2. J Biol Chem 277: 12622-12631, 2002.

25. Chen H, Pong RC, Wang Z and Hsieh JT: Differential regulation of the human gene $D A B 2 I P$ in normal and malignant prostatic epithelia: Cloning and characterization. Genomics 79: 573-581, 2002.

26. Wu K, Liu J, Tseng SF, Gore C, Ning Z, Sharifi N, Fazli L, Gleave M, Kapur P, Xiao G, et al: The role of DAB2IP in androgen receptor activation during prostate cancer progression. Oncogene 33: 1954-1963, 2014.

27. Valentino E, Bellazzo A, Di Minin G, Sicari D, Apollonio M, Scognamiglio G, Di Bonito M, Botti G, Del Sal G and Collavin L: Mutant p53 potentiates the oncogenic effects of insulin by inhibiting the tumor suppressor DAB2IP. Proc Natl Acad Sci USA 114: 7623-7628, 2017.

28. Ren G, Baritaki S, Marathe H, Feng J, Park S, Beach S, Bazeley PS, Beshir AB, Fenteany G, Mehra R, et al: Polycomb protein EZH2 regulates tumor invasion via the transcriptional repression of the metastasis suppressor RKIP in breast and prostate cancer. Cancer Res 72: 3091-3104, 2012. 
29. Hsieh JT, Karam JA and Min W: Genetic and biologic evidence that implicates a gene in aggressive prostate cancer. J Natl Cancer Inst 99: 1823-1824, 2007.

30. Dote H, Toyooka S, Tsukuda K, Yano M, Ouchida M, Doihara H, Suzuki M, Chen H, Hsieh JT, Gazdar AF and Shimizu N: Aberrant promoter methylation in human DAB2 interactive protein $(h D A B 2 I P)$ gene in breast cancer. Clin Cancer Res 10: 2082-2089, 2004.

31. Xie D, Gore C, Liu J, Pong RC, Mason R, Hao G, Long M, Kabbani W, Yu L, Zhang H, et al: Role of DAB2IP in modulating epithelial-to-mesenchymal transition and prostate cancer metastasis. Proc Natl Acad Sci USA 107: 2485-2490, 2010

32. Xie D, Gore C, Zhou J, Pong RC, Zhang H, Yu L, Vessella RL, Min W and Hsieh JT: DAB2IP coordinates both PI3K-Akt and ASK1 pathways for cell survival and apoptosis. Proc Natl Acad Sci USA 106: 19878-19883, 2009.

33. Ryan MB, Finn AJ, Pedone KH, Thomas NE, Der CJ and Cox AD: ERK/MAPK signaling drives overexpression of the Rac-GEF, PREX1, in BRAF- and NRAS-mutant melanoma. Mol Cancer Res 14: 1009-1018, 2016.
34. Vial E, Sahai E and Marshall CJ: ERK-MAPK signaling coordinately regulates activity of Racl and RhoA for tumor cell motility. Cancer Cell 4: 67-79, 2003.

35. Widmann C, Gibson S, Jarpe MB and Johnson GL: Mitogenactivated protein kinase: Conservation of a three-kinase module from yeast to human. Physiol Rev 79: 143-180, 1999.

36. Robinson MJ and Cobb MH: Mitogen-activated protein kinase pathways. Curr Opin Cell Biol 9: 180-186, 1997.

37. Datta A, Kim H, Lal M, McGee L, Johnson A, Moustafa AA, Jones JC, Mondal D, Ferrer $M$ and Abdel-Mageed AB: Manumycin A suppresses exosome biogenesis and secretion via targeted inhibition of Ras/Raf/ERK1/2 signaling and hnRNP H1 in castration-resistant prostate cancer cells. Cancer Lett 408: 73-81, 2017

38. Zhang X, Liu G, Ding L, Jiang T, Shao S, Gao Y and Lu Y: HOXA3 promotes tumor growth of human colon cancer through activating EGFR/Ras/Raf/MEK/ERK signaling pathway. J Cell Biochem 119: 2864-2874, 2018. 